\title{
Editorial
}

\section{Computer Models and Simulations in Scientific Practice}

The special issue ${ }^{1}$ at hand focuses on computer models and simulations as an increasingly important set of tools, methods and practices that complement and, in part, substitute for the traditional theoretical and experimental modes of doing science. Computer modelling and simulation play prominent roles in scientific fields as diverse as physics, meteorology, neuroscience, nanoscience, sociology, economics, and archaeology. The importance of models does not limit itself to science. Today models and simulations are of prime importance also in social, economic and environmental prediction and decision-making. Yet, as the discussion of climate change shows, there is some uncertainty in the air as to whether and on what grounds we should trust model results. Thus from the point of view of scientific practice, computer models and simulations are particularly intriguing, being at the same time both highly productive and contested. The three contributions of this special issue invite us to consider the various ways in which computer models and simulations influence the production of scientific knowledge, how they are assessed and how they become embedded in the wider contexts of scientific practice. The articles address computer models and simulations in case studies on brain science (Peter Asaro), nanotechnology (Ann Johnson) and meteorology (Mikaela Sundberg), thus providing a novel perspective on rapidly developing fields of study. The authors draw together lines of reasoning and traditions of thought from the history, philosophy and sociology of science.

\section{Earlier Approaches to Models}

The discussion of models has heterogeneous beginnings, testifying to a variety of theoretical, formal, and practical aspirations that appear to have different and even conflicting goals. The interest in models can be dated back at least to the mechanistic paradigm prominent in nineteenth century physics, of which the French philosopher of science Pierre Duhem wrote disapprovingly: "We thought we were entering the tranquil and neatly ordered abode of reason, but we find ourselves in the factory" (in Hesse, 1966: 2). This interest in mechanical models was superseded by logical positivism, which gave altogether a different role - and, consequently, a different characterisation - to models in scientific endeavour. The task of a model was to provide an interpretation to a theory, which was conceived of as a 
purely syntactic structure consisting of a set of axioms. Without an interpretation the skeletal structure of the theory could not provide information of the world. In the 1960s this axiomatic view of theories became contested by the semantic conception of models, which was inspired by mathematics and computer science. The semantic view replaced the syntactic formulation of a theory with a theory's models. According to the semantic conception, theories are not assemblages of propositions or statements, but rather assemblages of models, which in turn are understood in logico-mathematical terms. The semantic conception of models is still perhaps the most accepted view on models among the philosophers of science. Of the semantic approaches to models (and theories) the best known are those of van Fraassen (1980) and Giere (1988).

As opposed to the older mechanical view of models, the syntactic and semantic conceptions of models developed by philosophers of science considered models predominantly as theoretical, abstract and ideal entities. The basic aim of these attempts was to establish, within a formal framework, what scientific models (and theories) are. However, alongside the emergence of the semantic conception of models, also the older, more practice-oriented approach to models was revived at the turn of the 1960s. Partly inspired by the socalled historicist turn in the philosophy of science, several philosophers sought to study the role and place of models in scientific research. Issues such as scientific reasoning, scientific discovery and theory change prompted these philosophers to focus on models (Bailer-Jones, 1999: 31). Achinstein (1968), Black
(1962), Hesse (1966), and Hutten (1954) likened models to analogies and metaphors in their attempt to understand how models function in scientific reasoning and discovery. Moreover, both Max Black and Peter Achinstein considered scale models as the prototypical models, and they stressed the importance of the manipulability or "workability" of models - a theme that has become central again in recent discussions of models. Since the 1990s the practice-oriented approach to models has once again gained momentum flowing from different yet interdependent directions. ${ }^{2}$ Interestingly, this discussion has already now created a common ground between philosophers and STS researchers, both of whom consider models and simulations an important new area of study.

\section{Philosophy of Science Meets STS}

Traditionally, there has been some division of labour between philosophers of science and STS researchers. The discussion of models has partly reconfigured this scheme. While philosophers have tended to concentrate on theories and concepts, STS scholars have instead been fascinated by experimentation and the material work in laboratories. However, as the practice-orientation has gained a stronger hold of the philosophy of science, philosophers have caught sight also of models as important purveyors of scientific knowledge. ${ }^{3}$ In the meantime, STS scholars have, in turn, extended their laboratory studies to the "dry labs" provided by models and simulations. In our opinion, the studies of models by philosophers and STS scholars can be seen to interact with, intersect and complement one another, 
with the practice-orientation laying out a bridge between the two. Two recent, influential publications on models provide an interesting example of the aforementioned dynamics: the volume Models as Mediators (Morgan and Morrison, 1999), and the special issue Modeling and Simulation of the journal Science in Context (Sismondo and Gissis, 1999). Whereas Morrison and Morgan laid the basis for a philosophical research program that addresses models from the point of view of scientific practice (Morrison and Morgan, 1999), several contributions of the special issue of $S c i$ ence in Context were already in the business of doing that kind of work.

The present burgeoning interest in models can also be attributed to the rapid development of computers and computational methods. The onset of computational methods in science took place in the 1950s when researchers started to use simulation methods in such diverse fields as nuclear physics, climate research, operation research and game theory (Galison, 1996). This development is continuing at increasing pace with new areas of research and application, and potential disciplines emerging, which often carry the prefix "computational" in their names (cf. Johnson, 2006). Especially for science studies researchers this development has raised the more general question of whether computational methods present us with new modes of scientific practice and knowledge production.

Computer-based models and simulations do not fit comfortably in the categories of either theory or experiment. As a result of having characteristics of both, simulations behave like theoretical work in one respect and like experimentation in another (Sismondo, 1999; Dowling, 1999). A close investigation of how simulation mimics complex physical systems exhibits that the scientific practice of simulation involves a complex chain of inferences and a whole series of approximations and idealizations - a process that has been claimed to have its own epistemology (Winsberg, 1999; 2003). ${ }^{4}$ The intermediary status of computer modelling and simulation, however, does not solely concern their relation with theory and experiment. Modelling and simulation also have the potential to link up other kinds of domains by constituting "trading zones" (Galison, 1996) in which different activities can be locally coordinated.

Based on the observation that computer models play a prominent role at interfaces between different domains, especially science studies researchers have focused on the science-policy and the science-public interface. This explains the relative abundance of STS case studies on climate research and environmental modelling. The studies exhibit computer modelling as a simultaneously scientific and political activity, making visible such issues as the negotiation of scientific uncertainty and the authority of scientific knowledge (cf. Edwards, 1999; Shackley, 2001; Shackley and Wynne, 1996; van der Sluijs et al., 1998; Yearley, 1999). Because of their considerable complexity, environmental computer models bring to the fore also another topic of concern to both scientists and the public: the task of validating simulation. Science studies scholars have addressed the issue of the reliability of models and simulations both as an epistemological challenge and as a practical accomplish- 
ment of the scientists concerned (Oreskes et al., 1994; Oreskes, 1998; Wynne, 1996).

\section{Practice Approach to Models and Simulations}

During the last few years, a shared interest in the role of modelling and simulation in scientific practice has created common ground among philosophers, historians, and sociologists of science. This special issue is an indication of the new trend (for another collective volume, see Lenhard et al., 2006). The trend is largely due to the practice-oriented approach to science and knowledge, which became prominent within social studies of science in the 1980s (Pickering, 1992). In addition, the practice orientation has gained a stronger hold of the philosophy of science (Giere, 1999) and linked up with contemporary social theory (Schatzki et al., 2001).

From the practice point of view one promising perspective on models and simulations considers them as objects that draw together the entire web of activities in which they are enlaced. Stimulated by Rheinberger's (1997) and Knorr Cetina's (2001) work on the dynamics of scientific and technical objects, computer models and simulations have been analyzed as "unfolding" and "multiplex" entities (Merz, 1999): they allow actors to hold different conceptions of the same artefact and serve multiple purposes. Yet, as well as other models, computer models may be resistant to particular usages while affording others, often in an unintended manner. This is due to their material embodiment, which in the case of computer models and simulations is tied to a specific machine, the computer. Thus computer models can be conceptualized as "epistemic artifacts", whose epistemic value is due to their materially embodied constraints and productivity (Knuuttila and Voutilainen, 2003; Knuuttila, 2006a).

Once models and simulations are treated as unfolding scientific objects their respective biographies also become possible objects of study (Daston, 2000). Tracing the life span or curriculum of a specific computer model offers a fruitful way to understand how models become research tools within the communities that build and use them. By analyzing their constructed nature we learn about the ingredients (i.e. technical solutions, data or methods) that are brought into a model. Boumans (1999) has approached the construction process of models through an analogy of "baking a cake without a recipe" whereby the various "ingredients" needed are being "moulded" into a model. This perspective also renders visible the specific skills and expertise that emerge in the very course of the modelling process (Mattila, 2005; 2006). Moreover, such analysis reveals the inherent interdisciplinarity of computational science: resources from mathematics, statistics, and computer science are needed in addition to the substance knowledge of specific fields.

Prompted by the aforementioned work on models as mediators (e.g. Morgan and Morrison, 1999), a practiceoriented account of modelling turns to mediation, which we understand in a very wide sense covering complex semiotic and objectual processes and including various actors and different institutions. In this reading, mediation spans not only between the worlds of "theory" 
and "data", as Morrison and Morgan (1999) originally suggested. It applies similarly to all boundary-crossing practices, whether they take place between different areas of research, or between science and other areas of competence. Additionally, what comes into view, are the mechanisms by way of which computer models and simulations connect different temporal phases of research projects, or allow scientists to integrate heterogeneous bodies of knowledge or data (Merz, 2006; Knuuttila, 2006b). The practice approach considers mediation a practical accomplishment, the specific conditions and modes of which need to be explored in a more systematic fashion than has been done so far.

\section{Exploring Novel Fields}

The common thread running through the contributions of this special issue is indeed the complexity of the computer models themselves and the different routes through which computer modelling and simulation bear on scientific knowledge.

Peter Asaro investigates the role of electronic brains in the mid- $20^{\text {th }}$ century cybernetics movement. He shows how the electro-mechanical models, such as the "Homeostat" and the "Tortoise" successfully advanced the mechanistic view of the mind by creating a linkage between low-level physiological mechanisms and higher level behaviours. The electronic brains succeeded in this task, Asaro claims, because they provided scientists with working models whose productivity was largely due to their material agency. Electronic brains demonstrated by their behaviour that simple mechanisms could exhibit complex bio- logical and behavioural phenomena. Moreover, as built machines they also yielded unexpected results as they could be materially manipulated in ways that were not intended features of their design. Thus Asaro argues for the importance of the "synthetic method" in gaining knowledge. The synthetic method consists of constructing concrete objects, the properties and behaviours of which can be directly examined. Such method also explains why technological advances often constitute inseparable elements of the scientific endeavour.

Like Asaro, Ann Johnson is interested in the relationship between technological opportunities and scientific practice. In her article, she sets out to deconstruct "myths" about simulation, based on her case study on computational nanotechnology. One of these myths asserts that simulations are attractive because they are less costly than experiments. Johnson does not buy into this account, which she characterizes as unduly simplistic. Instead, she carefully spells out the variety of resources that simulations depend upon and shows that human, financial, and technological resources shape knowledge construction, enable and restrain the choices and orientations of researchers. From the perspective of Johnson's approach, the endeavour to decouple and weigh against each other "simulation" and "experiment" appears as futile. Simulations and laboratory science are interdependent, the construction of simulations is closely coupled to the manufacture of empirical data already on the level of stated objectives of various research institutes. With a focus on three different institutional settings for computational nanotechnology in the U.S., Johnson shows how organiza- 
tional structures, research programs, cooperation patterns, epistemic practices, and institutional arrangements are integrated into the way "science makes itself."

Mikaela Sundberg addresses the relation between simulation modelling, experiment and data, but she chooses another angle of approach. In her study of model evaluation in meteorology, Sundberg raises the question why modellers are less strict than would be expected about the requirement that model output fit observation data. In providing an answer, Sundberg draws on social world theory to analyse tensions in the evaluation of climate models. What is of interest here is that two different social worlds, those of simulation modelling and field experimentation, are actually seen to emerge within a single field: meteorology. Juxtaposing the interview statements of both modellers and experimentalists, Sundberg provides interesting insight into the boundary work and intersections taking place between the two social worlds. From this point of view the experimentalists' and modellers' conceptions of each other are particularly intriguing. Sundberg argues that the tensions between the modellers and the experimentalists should not be seen as contingent phenomena, but rather arise from their respective practices, each with a set of distinct purposes, criteria and tools.

\section{Challenges for Further Research}

The practice-approach promoted in this issue brings about accounts of modelling and simulation that disclose the unwieldy and varied stuff science is made of. Apart from being results of interdisciplinary work, the computer models and simulations of interest in the following articles require many different resources (financial, technological, institutional, etc.). They assume autonomous agency, and their potential to mediate between different theories, scientific activities and social worlds needs to be carefully negotiated among the actors concerned. As a consequence, computer models and simulations cannot be regarded simply as extensions of either theory or experiment, and neither do they merely provide a missing link between the two. Studying models and simulations in practice requires one to carefully consider different disciplinary cultures, institutional frameworks and laboratory settings, that is, the social environments and the objectual configurations within which models and simulations assume their specific roles and functions. This raises several questions such as: Should computer modelling and simulation be considered a scientific practice of its own that creates new epistemic possibilities, criteria, and standards? What is the role of material agency in modelling in general, and in computer modelling and simulation in particular? What kinds of resources are needed in computational sciences and how do they influence the research projects undertaken, i.e. the questions asked, the methods applied, etc.? The contributions of these three articles go some way in answering these questions, yet the work on addressing computer models and simulations from the perspective of scientific practice has only just begun.

\section{Notes}

1 The idea of the special issue goes back to 
a series of conference sessions on models and simulations, which we organized (together with Cathrine Hasse and Johannes Lenhard). The sessions took place at the 4S (Society for Social Studies of Science) Meeting in Atlanta, Georgia in October 2003 and at the joint Conference of the Society for Social Studies of Science (4S) and the European Association for the Study of Science and Technology (EASST) in Paris, August 2004. We wish to thank all colleagues who discussed their work with us at the occasion of these meetings.

2 Parallel to the developments in the philosophy of science, models have attracted growing interest in cognitive science. This has led philosophers of science into dialogue with psychologists and cognitive scientists in what is now called model-based reasoning in science (cf. e.g. Magnani etal., 1999).

3 The very discussion of models in philosophy has indeed been motivated by practice-oriented considerations - even the proponents of the semantic conception understood themselves as providing a more realistic picture of theories.

4 For a philosophically oriented discussion on simulation see also the contributions of the PSA 1990 symposium on simulation (Fine et al., 1991), Keller (2003), Hartman (1996), Humphreys (2004), and Morgan (2003).

\section{References}

Achinstein, P.

1968 Concepts of Science. Baltimore: Johns Hopkins Press.

Bailer-Jones, D.M.

1999 "Tracing the Development of Models in the Philosophy of Science." Pp. 23-40 in Magnani, Nersessian \& Thagard (eds.), Model-Based Reasoning in SciBlack, M. entific Discovery. New York: Kluwer.

1962 Models and Metaphors. Ithaca: Cornell University Press.
Boumans, M.

1999 “Built-in justification.” Pp. 66-96 in Morgan \& Morrison (eds.), Models as Mediators: Perspectives on Natural and Social Sciences. Cambridge: Cambridge University Press.

Daston, L. (ed.)

2000 Biographies of Scientific Objects. Chicago: University of Chicago Press.

Dowling, D.

1999 "Experimenting on Theories." Science in Context 12 (2): 261-273.

Edwards, P.N.

1999 "Global Climate Science, Uncertainty and Politics: Data-laden Models, Model-filtered Data." Science in Culture 8 (4): 437-472.

Fine, A., Forbes, M. \& Wessels, L. (eds.)

1991 PSA 1990, Volume 2. East Lansing: Philosophy of Science Association.

Galison, P.L.

1996 "Computer Simulations and the Trading Zone." Pp. 118-157 in Galison (ed.), The Disunity of Science. Stanford: Stanford University Press.

Giere, R.N.

1988 Explaining Science: A Cognitive Approach. Chicago and London: The University of Chicago Press.

1999 Science without Laws. Chicago and London: The University of Chicago Press.

Hartmann, S.

1996 "The World as a Process: Simulations in Natural and Social Sciences." Pp. 77100 in Hegselman, Mueller \& Troitzsch (eds.), Modelling and Simulation in the Social Sciences from the Philosophy of Science Point of View. Dordrecht: Kluwer.

Hesse, M.

1966 Models and Analogies in Science. Milwaukee: University of Notre Dame Press.

Hutten, E.H.

1954 “The Role of Models in Physics." British Journal for the Philosophy of Science 4: 284-301.

Humphreys, $\mathrm{P}$.

2004 Extending Ourselves: Computational Science, Empiricism, and Scientific Method. Oxford: Oxford University Press. 
Johnson, A.

2006 “The Shape of Molecules to Come.” Pp. 25-39 in Lenhard, Küppers \& Shinn (eds.), Simulation: Pragmatic Constructions of Reality - Sociology of the Sciences, vol. 25. Dordrecht: Springer. (forthcoming)

Keller, E.F.

2003 "Models, Simulation, and 'Computer Experiments." Pp. 198-215 in Radder (ed.), The Philosophy of Scientific Experimentation. Pittsburgh: University of Pittsburgh Press.

Knorr Cetina, K.

2001 “Objectual Practice.” Pp. 175-188 in Schatzki, Knorr Cetina \& von Savigny, The Practice Turn in Contemporary Theory. London \& NewYork: Routledge.

Knuuttila, T.

2006a "Models, Representation, and Mediation." Philosophy of Science 73. (forthcoming)

2006b "From Representation to Production: Parsers and Parsing in Language Technology." Pp. 41-55 in Lenhard, Küppers \& Shinn (eds.), Simulation: Pragmatic Constructions of Reality - Sociology of the Sciences, vol. 25. Dordrecht: Springer. (forthcoming)

Knuuttila, T. \& Voutilainen, A.

2003 "A Parser as an Epistemic Artifact: A Material View on Models." Philosophy of Science 70: 1484-1495.

Lenhard, J., Küppers, G. \& Shinn, T. (eds.)

2006 Simulation: Pragmatic Constructions of Reality - Sociology of the Sciences, vol. 25. Dordrecht: Springer. (forthcoming)

Magnani, L., Nercessian, N. \& Thagard, P. (eds.) 1999 Model-Based Reasoning in Scientific Discovery. New York, Boston, London, Moscow: Kluwer Academic/Plenum.

Mattila, E.

2005 “Interdisciplinarity 'In the Making': Modelling Infectious Diseases.” Perspectives on Science 13(4): 531-553.

2006 "Struggle between Specificity and Generality: How Do Infectious Disease Models Become a Simulation Platform?" Pp. 125-138 in Lenhard, Küppers \& Shinn (eds.), Simulation: Pragmatic Constructions of Reality - Sociology of the Sciences, vol. 25. Dordrecht: Springer. (forthcoming)
Merz, M.

1999 "Multiplex and Unfolding: Computer Simulation in Particle Physics." Science in Context 12 (2): 293-316.

2006 "Locating the Dry Lab on the Lab Map." Pp. 155-172 in Lenhard, Küppers \& Shinn (eds.), Simulation: Pragmatic Constructions of Reality - Sociology of the Sciences, vol. 25. Dordrecht: Springer. (forthcoming)

Morgan, M.S.

2003 "Experiments without Material Intervention: Model Experiments, Virtual Experiments, and Virtually Experiments." Pp. 216-235 in Radder (ed.), The Philosophy of Scientific Experimentation. Pittsburgh: University of Pittsburgh Press.

Morgan, M.S. \& Morrison, M. (eds.)

1999 Models as Mediators: Perspectives on Natural and Social Science. Cambridge, UK: Cambridge University Press.

Morrison, M. \& Morgan, M.S.

1999 "Models as Mediating Instruments." Pp. 10-37 in Morgan \& Morrison (eds.), Models as Mediators: Perspectives on Natural and Social Science. Cambridge: Cambridge University Press.

Oreskes, N.

1998 "Evaluation (Not Validation) of Quantitative Models." Environmental Health Perspectives 106 (Supplement 6): 14531460.

Oreskes, N., Shrader-Frechette, K. \& Belitz, K.

1994 "Verification, Validation, and Confirmation of Numerical Models in the Earth Sciences." Science 263: 641-646.

Pickering, A. (ed.)

1992 Science as Practice and Culture. Chicago: University of Chicago Press.

Rheinberger, H.-J.

1997 Toward a History of Epistemic Things: Synthesizing Proteins in the Test Tube. Stanford, CA: Stanford University Press.

Schatzki, T.R., Knorr Cetina, K. \& von

Savigny, E. (eds.)

2001 The Practice Turn in Contemporary Theory. London \& NewYork: Routledge. 
Shackley, S.

2001 "Epistemic Lifestyles in Climate Change Modeling." Pp. 109-133 in Miller \& Edwards (eds.), Changing the Atmosphere: Expert Knowledge and Environmental Governance. Cambridge MA: MIT Press.

Shackley, S. \&Wynne, B.

1996 "Representing Uncertainty on Global Climate Change and Policy: BoundaryOrdering Devices and Authority." Science, Technology, \& Human Values 21 (3): 275-301.

Sismondo, S.

1999 "Models, Simulations, and Their Objects." Science in Context 12 (2): 247 260.

Sismondo, S. \& Gissis, S. (eds.)

1999 Modeling and Simulation, special issue of Science in Context 12 (2).

van der Sluijs, J. et al.

1998 "Anchoring Devices in Science for Policy: The Case of Consensus around Climate Sensitivity." Social Studies of Science 28 (2): 291-323.

van Fraassen, B.

1980 The Scientific Image. Oxford: Oxford University Press.

Winsberg, E.

1999 "Sanctioning Models: The Epistemology of Simulation." Science in Context 12 (2): 275-292.

2003 "Simulated Experiments: Methodology for a Virtual World." Philosophy of Science 70: 105-125.

Wynne, B.

1996 "SSK's Identity Parade: Signing-Up, Offan-On." Social Studies of Science 26 (2): 357-391.

Yearley, S.

1999 “Computer Models and the Public's Understanding of Science: A CaseStudy Analysis." Social Studies of Science 29 (6): 845-866.

\section{Guest Editors}

Tarja Knuuttila, Department of Philosophy, University of Helsinki, Finland

Martina Merz,

Technology and Society Laboratory, EMPA St Gallen, and OSPS, University of Lausanne, Switzerland

Erika Mattila

Department of Economic History, London School of Economics and Political Science, UK and Department of Philosophy, University of Helsinki, Finland 